\title{
Article
}

\section{Monodispersed Pd Nanoparticles for Acetylene Selective Hydrogenation: Particle Size and Support Effects}

Marina Ruta, Natalia Semagina, and Lioubov Kiwi-Minsker

J. Phys. Chem. C, 2008, 112 (35), 13635-13641• DOI: 10.1021/jp803800w • Publication Date (Web): 12 August 2008

Downloaded from http://pubs.acs.org on February 12, 2009

\section{More About This Article}

Additional resources and features associated with this article are available within the HTML version:

- Supporting Information

- $\quad$ Access to high resolution figures

- $\quad$ Links to articles and content related to this article

- Copyright permission to reproduce figures and/or text from this article

\section{View the Full Text HTML}




\title{
Monodispersed Pd Nanoparticles for Acetylene Selective Hydrogenation: Particle Size and Support Effects
}

\author{
Marina Ruta, Natalia Semagina, and Lioubov Kiwi-Minsker* \\ Group of Chemical Reaction Engineering, Ecole Polytechnique Fédérale de Lausanne, \\ GGRC-EPFL, Station 6, CH-1015 Lausanne, Switzerland
}

Received: April 30, 2008; Revised Manuscript Received: June 13, 2008

\begin{abstract}
Monodispersed Pd nanoparticles (8,11, and $13 \mathrm{~nm}$ in diameter) as confirmed by high resolution transmission electron microscopy were prepared via the reverse microemulsion method and deposited on structured supports consisting of carbon nanofibers (CNF) grown on sintered metal fibers (SMF). The CNF/SMF supports were subjected to oxidative treatments to introduce O-functional groups on the CNF surface. These groups were characterized by temperature-programmed decomposition (TPD) and X-ray photoelectron spectroscopy. The catalysts were used to study (a) the effect of Pd size and (b) the effect of the support nature on the selective acetylene hydrogenation. Antipathetic size dependence of TOF disappeared at particle size bigger than $11 \mathrm{~nm}$. Initial selectivity to ethylene was found size-independent. The deactivation due to coke deposition was faster for smaller particles. The structure-sensitivity relations for the catalysts investigated are discussed in terms of "geometric" and "electronic nature" of the size effect and rationalized regarding $\mathrm{Pd}-\mathrm{C}_{\mathrm{x}}$ phase formation which is size-dependent. Supports with increased acidity diminished the formation of coke and changed the byproduct distribution toward ethane.
\end{abstract}

\section{Introduction}

The structure-sensitivity of catalytic hydrogenation of unsaturated hydrocarbons over noble metal nanoparticles have already been reported. ${ }^{1-6}$ A change of selectivity and a higher turnover frequency (TOF) occur when the size of the metal particles increases. ${ }^{7,8}$ This change is explained by electronic and/or geometric effects caused by the change of the ratio of the different types of metal surface atoms with variation in particle size. Large particles possess crystal planes with atoms having high coordination numbers such as terrace atoms. In small particles the surface atoms with low coordination numbers (edge and corner) predominate. When TOF is calculated not per total surface atoms but per a specific atom, a dependence of TOF on the particle size may disappear, indicating which surface atoms are the active sites. ${ }^{9,10}$ These reactions are considered as "structure-sensitive" but size-independent.

Various explanations have been offered for the structuresensitivity of alkyne hydrogenations regarding the activity and selectivity. Some authors propose the surface and/or subsurface carbon $\left(\mathrm{Pd}-\mathrm{C}_{x}\right)$ to be responsible for the observed phenomena. ${ }^{11}$ Recently, a detailed study on alkyne hydrogenation over $\mathrm{Pd}$ catalysts demonstrated that the $\mathrm{Pd}-\mathrm{C}_{x}$ phase builds up within the initial reaction stage and is responsible for the catalyst activity/selectivity. ${ }^{12}$ The formation of a $\mathrm{Pd}-\mathrm{C}_{x}$ phase is a structure-sensitive reaction, leading to the dependence of the catalytic properties on the size of the $\mathrm{Pd}$ nanoparticles. Moreover, carbonaceous overlayers on the Pd surface may serve as a selectivity modifier by creating ensembles of different sizes with a variable number of surface atoms available for the adsorption. This leads to different adsorption geometries of the reacting molecules, rendering different reaction products.

During the acetylene hydrogenation over Pd nanoparticles, the TOF increases with particle size even for particles bigger

* Corresponding author. E-mail: lioubov.kiwi-minsker@epfl.ch, tel: +41 21-693 3182; fax: +41-21-693 6190. than $5 \mathrm{~nm}$ which do not exhibit any important change in the surface atom statistic. ${ }^{1,3}$ Borodzinsky ${ }^{6}$ reported the TOF increase with $\mathrm{Pd}$ size up to $26 \mathrm{~nm}$ over $\mathrm{Pd} / \mathrm{SiO}_{2}$ catalysts with $\mathrm{Pd}$ diameter of $4,5,7,16$, and $26 \mathrm{~nm}$. The size effect observed was claimed to be "geometric" in nature since the catalysis involved large ensembles of surface atoms (active sites). In our previous publication on the acetylene hydrogenation over $\mathrm{Pd}$ nanoparticles $^{13}$ supported on carbon nanofibers (CNF) the reaction was found to be size-dependent with a decrease of TOF 1 order of magnitude for particles smaller than $3-4 \mathrm{~nm}$. It is important to note that all studies on the size effect during acetylene hydrogenation have been carried out with polydispersed Pd nanoparticles. Moreover, different methods of catalyst preparation and the different nature of the supports together with nanoparticle size distribution may disguise the size effect. Important advances in colloidal preparation of metal nanoparticles bring new opportunities for studies on the size-effect relations. Recently, we showed the utilization of monodispersed $\mathrm{Pd}$ nanoparticles isolated from a reverse microemulsion (ME) in size-effect studies of 2-methyl-3-butyn-2-ol ${ }^{9}$ and 1-hexyne liquid-phase hydrogenation. ${ }^{14}$ Reverse ME technique allows the control of the metal particle size by the variation of the waterto-surfactant ratio. ${ }^{15-17}$ Both previous works on Pd size effect showed different results: hydrogenation of 2-methyl-3-butyn2-ol was found to be size-independent, while in 1-hexyne hydrogenation there was 1 order of magnitude TOF increase when comparing 11 and $13 \mathrm{~nm}$ particles. This dependence of size effect on the substrate nature shows a need for further sizeeffect studies with monodispersed particles for a wide range of hydrogenation reactions.

The aim of this work is to investigate size effect of the acetylene-selective hydrogenation over monodispersed Pd nanoparticles in the size region of 8-13 nm. Precise control over the particle diameter allows determination of the critical particle size, above which no size dependence of TOF is observed. Since gas-phase hydrogenations cannot be carried out over unsup- 
TABLE 1: Characteristics of the Catalysts Used during the Study

\begin{tabular}{|c|c|c|c|c|c|c|}
\hline catalyst & support & support pretreatment & method of preparation & Pd loading (wt $\%$ ) & Pd particle size $(\mathrm{nm})$ & Pd dispersion (\%) \\
\hline A & $\mathrm{CNF} / \mathrm{SMF}_{\text {Inconel }}$ & - & ME & 0.18 & 8 & $16.9^{a}$ \\
\hline B & $\mathrm{CNF}_{\mathrm{SMF}}$ Inconel & - & ME & 0.18 & 11 & $13.7^{a}$ \\
\hline $\mathrm{C}$ & $\mathrm{CNF}_{\mathrm{SMF}} \mathrm{Snconel}$ & - & ME & 0.18 & 13 & $11.9^{a}$ \\
\hline $\mathrm{E}$ & $\mathrm{CNF} / \mathrm{SMF}_{\text {Inconel }} \mathrm{l}$ & $\mathrm{O}_{3}$ & $\mathrm{ME}$ & 0.18 & 11 & $13.7^{a}$ \\
\hline $\mathrm{F}$ & $\mathrm{CNF} / \mathrm{SMF}_{\text {Inconel }}$ & $\mathrm{H}_{2} \mathrm{O}_{2}$ & ion exchange & 0.15 & 5.5 & $19.8^{b}$ \\
\hline
\end{tabular}

${ }^{a}$ Dispersion was calculated by statistical method. ${ }^{10}{ }^{b}$ Measured by CO chemisorption.

ported Pd nanoparticles, a composite material based on carbon nanofibers $(\mathrm{CNF})$ grown on sintered metal fibers $\left(\mathrm{SMF}_{\text {Inconel }}\right)$ filter was used as a Pd support, ${ }^{18}$ in a continuous fixed-bed reactor. There are two main reasons for this choice: (1) the open structure of CNF/SMF filters presents a low pressure drop through the reactor together with even gas-flow distribution; (2) the mesoporous morphology of the graphitic CNF ensures low mass-transfer resistance, and the high thermoconductivity of $\mathrm{CNF} / \mathrm{SMF}_{\text {Inconel }}$ allows strict temperature control during the exothermic acetylene hydrogenation. ${ }^{13,19,20}$

Another major issue in the acetylene hydrogenation is the selectivity to ethylene, since this reaction is performed industrially to remove acetylene impurities from ethylene feedstock. ${ }^{21}$ The control of the oligomerization of acetylene, which causes the deactivation of the catalyst by covering the metal surface with polyolefin (green-oil) ${ }^{22-26}$ is also important. The second part of this work presents the effect of the CNF-support acidity on the catalyst performance. The $\mathrm{CNF}$ acidity was increased by oxidative treatment of $\mathrm{CNF} / \mathrm{SMF}_{\text {Inconel }}$ with $\mathrm{H}_{2} \mathrm{O}_{2}$ or plasmagenerated $\mathrm{O}_{3}$.

\section{Experimental Section}

2.1. Materials. Sintered metal fibers (SMF) Bekipor ST 20AL3 (Bekaert Fiber Technology, Belgium) made of Inconel 601 (alloy composition: Ni 58-63\%; Cr 21-25\%; Al 1.4\%) in the form of panel (elementary filament diameter, $8 \mu \mathrm{m}$; panel thickness, $0.49 \mathrm{~mm}$, porosity, $81 \%$, weight, $750 \mathrm{~g} / \mathrm{m}^{2}$ ) were used as support for CNFs. The acetylene of $99.6 \%$ and other gases $>99.995 \%$ were purchased from Carbagas, Switzerland, and were used as received. Palladium chloride anhydrous (purum, p.a., Fluka), sodium chloride (purum, p.a., Fluka), tetraaminepalladium(II) chloride monohydrate $(99.99+\%$,Aldrich), isooctane (2,2,4-trimethylpentane, extra dry, with molecular sieves, water $<30 \mathrm{ppm}$, Acros Organics), hydrazinium hydroxide (for synthesis; Merck), 32\% ammonium hydroxide solution (extra pure, Merck), methanol (for analysis, ReactoLab C.A.), 35\% $\mathrm{H}_{2} \mathrm{O}_{2}$ aqueous solution (Fluka) were used as received. AOT (sodium di-2-ethylhexylsulfosuccinate, or docusate sodium salt, purum, $>96 \%$, Fluka) was vacuum-dried for $24 \mathrm{~h}$ at $333 \mathrm{~K}$ directly before use. All glassware was air-dried at $393 \mathrm{~K}$. Demineralized bidistilled water was used throughout the study.

2.2. Preparation, Activation, and Characterization of $\mathbf{C N F} / \mathbf{S M F}_{\text {Inconel. }}$ Prior to the CNF synthesis, the $\mathrm{SMF}_{\text {Inconel }}$ panels were oxidized in air at $650{ }^{\circ} \mathrm{C}$ for $3 \mathrm{~h}$. Carbon nanofibers (CNF) were grown on $\mathrm{SMF}_{\text {Inconel }}$ by decomposition of ethane in the presence of hydrogen. All preparation details and characterization of the $\mathrm{CNF} / \mathrm{SMF}_{\text {Inconel }}$ have been described elsewhere. ${ }^{18}$ Before the $\mathrm{Pd}$ deposition, $\mathrm{CNF} / \mathrm{SMF}$ Inconel supports were treated in an ultrasonic bath to remove nonanchored carbon $\left(<0.5\right.$ wt. \%). During this study, the composite CNF/SMF ${ }_{\text {Inconel }}$ supports underwent different pretreatments to functionalize the CNF surface. In the first case, these supports were activated in a $35 \% \mathrm{H}_{2} \mathrm{O}_{2}$ boiling aqueous solution for $4 \mathrm{~h}$ and then washed with water until neutral $\mathrm{pH}$ was attained. In the second case, the supports were treated for 30 min with plasma-generated $\mathrm{O}_{3}$ formed in a dielectric barrier discharge plasma reactor. ${ }^{27}$ The ozone concentration was monitored with an UV absorption monitor (API-450 NEMA), and after $30 \mathrm{~min}$ the output value was constant at $1100 \mathrm{ppm}$. The functional groups were subsequently characterized by temperature-programmed decomposition (TPD) in $\mathrm{He}(20 \mathrm{~mL} / \mathrm{min}$, ramp rate $20 \mathrm{~K} / \mathrm{min}$ from room temperature up to $1273 \mathrm{~K}$ ) using a Micromeritics AutoChem 2910 analyzer. The amounts of $\mathrm{CO}$ and $\mathrm{CO}_{2}$ desorbed were monitored with a ThermoStar-200 quadropole mass spectrometer (Pfeiffer Vacuum). X-ray photoelectron spectroscopy (XPS) analysis of the $\mathrm{CNF} / \mathrm{SMF}$ Inconel was also carried out before and after oxidative treatment; the system employed for the analysis was an Axis Ultra ESCA (Kratos, Manchester) with monochromated A1 K $\alpha$ radiation $(1486.6 \mathrm{eV})$.

2.3. Preparation and Characterization of Pd/CNF/SM$\mathbf{F}_{\text {Inconel }}$ Two methods for Pd deposition on $\mathrm{CNF} / \mathrm{SMF}_{\text {Inconel }}$ were used during this work. The catalysts and their characteristics are listed in Table 1. Catalysts $\mathrm{A}-\mathrm{E}$ were prepared via impregnation of $\mathrm{CNF} / \mathrm{SMF}_{\text {Inconel }}$ supports with a colloidal solution of $\mathrm{Pd}$ nanoparticles prepared beforehand using a modified reversed microemulsion (ME) technique reported elsewhere. ${ }^{9}$ Pd nanoparticles of 8,11 , and $13 \mathrm{~nm}$ diameter were synthesized in water/AOT/isooctane microemulsion at waterto-surfactant ratios of 4,5 , and 7 , respectively. The aqueous solution of $\mathrm{PdCl}_{2}\left(\mathrm{NH}_{3}\right)_{4}(0.05 \mathrm{M})$ was used as palladium precursor, adjusting the $\mathrm{pH}$ with ammonia to 9 . The $3 \mathrm{M}$ solution of hydrazine hydrate was used as a reducing agent, giving a hydrazine-to-Pd molar ratio of 60 to ensure the precursor reduction. The reverse ME-containing metal precursor or reducing agent was prepared by injecting the required amounts of the corresponding aqueous solution into $0.35 \mathrm{M}$ isooctane solution of AOT and then mixing for a few minutes to prepare the $\mathrm{Pd}$ nanoparticles. After a $1 \mathrm{~h}$ reduction, isooctane was evaporated in a rotary evaporator at $323 \mathrm{~K}$ and the nanoparticles were purified from the excess of surfactant by addition of methanol followed by centrifugation $(3 \times 30 \mathrm{~mL})$. The precipitate was redispersed in $12 \mathrm{~mL}$ of water by ultrasonic treatment for $20 \mathrm{~min}$. The black colloidal dispersion of $\mathrm{Pd}$ nanoparticles was used to impregnate the $\mathrm{CNF} / \mathrm{SMF}_{\text {Inconel }}$ support to give $0.18 \mathrm{wt}$. \% nominal Pd loading on the support. Pd content in the colloidal dispersion was determined by AAS. The impregnated support was air-dried at $393 \mathrm{~K}$.

$\mathrm{Pd}$ nanoparticles in catalysts $\mathrm{A}-\mathrm{E}$ were monodispersed $(<25 \%$ deviation from the average size) as confirmed by highresolution transmission electron microscopy (HR-TEM, Philips EM 430 ST). The instrument was equipped with an energydispersive X-ray (EDX) analyzer. The specimen sample for HRTEM consisted of supported Pd nanoparticles on CNF reduced with $10 \% \mathrm{H}_{2}$ in $\mathrm{Ar}$ (total flow $150 \mathrm{~mL}(\mathrm{STP}) / \mathrm{min}$ ) at $423 \mathrm{~K}$ for $1 \mathrm{~h}$ (same treatment performed in situ before the catalytic measurements) and removed from $\mathrm{SMF}_{\text {Inconel }}$ by ultrasonication $(2 \mathrm{~h})$. The sample was then deposited on a carbon film of a copper grid used in HRTEM. More than $99.5 \%$ of 
surfactant was removed during the washing procedure as was shown in the literature. ${ }^{9}$ In this study, Pd crystallinity and the particle size were also confirmed by X-ray diffraction performed in a $2 \theta$ range of $35-90^{\circ}$ on dried nanoparticles. Characteristic peaks of $\{111\},{ }^{28}\{200\},\{220\},\{311\},\{222\}$ planes of Pd fcc structure showed XRD patterns at $2 \theta$ of $40^{\circ}, 46.5^{\circ}, 67.9^{\circ}, 81.8^{\circ}$, $86.4^{\circ}$, respectively. Calculation of a mean $\mathrm{Pd}$ nanoparticle size using a Scherrer equation for the particles synthesized at waterto-surfactant ratios of 4 and 7 gave values of 8.3 and $12.7 \mathrm{~nm}$, respectively. The $\mathrm{Pd}$ dispersion was calculated considering the statistic of the surface atoms on a fcc cuboctahedron max- $\mathrm{B}_{5}$ crystallite. ${ }^{10}$

The diameter of the particle $d$ has been related to the total number of atoms $\left(N_{\mathrm{T}}\right)$ and the number of atoms at the surface $\left(N_{\mathrm{S}}\right)$, and then it was suggested that the face of the crystal anchored to the CNF corresponds to the (111) plane. The number of atoms of one of these planes $\left(N_{3,9}\right)$ was subtracted from the value of $N_{\mathrm{S}}$, and eventually the dispersion was obtained by the ratio between the modified value of $N_{\mathrm{S}}$ and $N_{\mathrm{T}}$.

Catalyst $\mathrm{F}$ was prepared, depositing $\mathrm{Pd}$ on activated $\mathrm{CNF} /$ $\mathrm{SMF}_{\text {Inconel }}$ via ion-exchange from an aqueous solution of $\mathrm{Na}_{2} \mathrm{PdCl}_{4}$ (by dissolving $\mathrm{PdCl}_{2}$ with 10 equivalents of $\mathrm{NaCl}$ ) for $4 \mathrm{~h}$. The concentration was set to obtain $5 \mathrm{wt} \% \mathrm{Pd}^{0}$ on $\mathrm{CNF}$. After the ion-exchange, the supported catalyst was rinsed with water and air-dried for $12 \mathrm{~h}$ at room temperature. It was subsequently reduced in $10 \% \mathrm{H}_{2}$ in $\mathrm{Ar}$ (total flow $150 \mathrm{~mL}$ (STP)/ $\mathrm{min})$ at $448 \mathrm{~K}$ overnight before the reaction. The residual $\mathrm{Pd}$ content in the aqueous solution was determined by atomic absorption spectroscopy (AAS) at $247.6 \mathrm{~nm}$ via a Shimadzu AA-6650 spectrometer with an air-acetylene flame: by difference from the initial concentration, the amount of Pd deposited could be estimated. In the case of Pd deposited by ion-exchange, it was not possible to apply the same statistical method to calculate $\mathrm{Pd}$ dispersion because of the broad particle-size distribution. Pulse CO chemisorption measurements at $323 \mathrm{~K}$ via an AutoChem 2910 instrument (Micromeritics SA, Norcross, GA, USA) allowed estimation of the metal dispersion after reductive treatment with $10 \% \mathrm{H}_{2}$ in $\mathrm{Ar}$ (total flow $150 \mathrm{~mL}$ $(\mathrm{STP}) / \mathrm{min}$ ) at $448 \mathrm{~K}$ overnight. The particle size, estimated by $\mathrm{CO}$ chemisorption, has to be considered as an average using the number of Pd atoms exposed on the surface layer.

2.4. Hydrogenation of Acetylene. Selective hydrogenation of acetylene to ethylene was carried out in a stainless steel tubular reactor (internal diameter $12 \mathrm{~mm}$ ); two disks of the Pdsupported catalyst ( $m_{\text {cat. }} \sim 180 \mathrm{mg}$ ) were placed perpendicular to the gas flow. The temperature was monitored with a thermocouple touching the catalyst inside the reactor and maintained constant using a reactor with an oil-circulated external jacket.

Catalysts $\mathrm{A}-\mathrm{E}$ were activated before the reaction in $10 \% \mathrm{H}_{2}$ in $\mathrm{Ar}$ (total flow $150 \mathrm{~mL}(\mathrm{STP}) / \mathrm{min}$ ) at $423 \mathrm{~K}$ for $1 \mathrm{~h}$. For the reaction, the mixture of $2 \mathrm{vol} . \%$ of acetylene, $\mathrm{C}_{2} \mathrm{H}_{2}$, and 4 vol.\% of $\mathrm{H}_{2}$ in $\mathrm{Ar}$ (total flow $700 \mathrm{~mL}$ (STP)/min) was used throughout the study. The mixture to the reactor inlet was controlled by mass flow controllers. The reaction temperature was set at 423 $\mathrm{K}$. Products were analyzed online by gas chromatography (HP 6890) using a Carboxen 1010 (Supelco) capillary column, a flame ionizator, and a thermal conductivity detector.

Catalyst performance was monitored within $6 \mathrm{~h}$ on-stream. Catalytic activity was expressed in terms of TOF $\left[\mathrm{s}^{-1}\right]$, calculated as the moles of acetylene converted per mole of surface Pd (total Pd mol multiplied by the dispersion) and per second. The reaction rate was calculated as the moles of acetylene converted per second and per gram of $\mathrm{Pd}$ on the

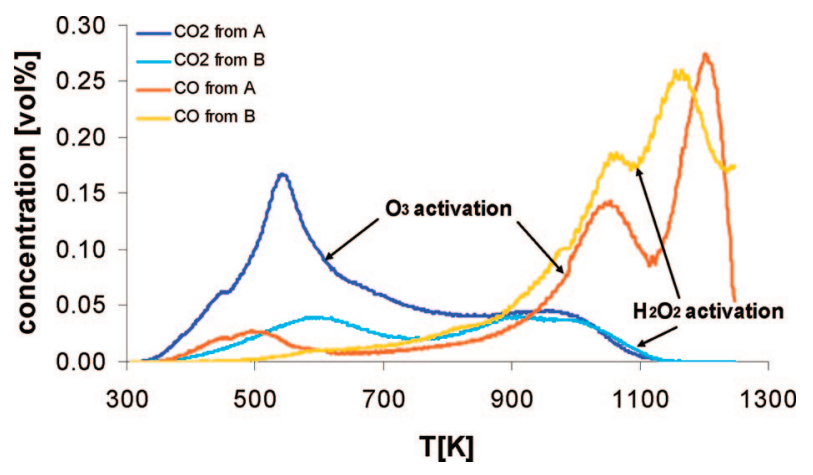

Figure 1. TPD profiles of $\mathrm{CNF} / \mathrm{SMF}_{\text {Inconel }}$ samples $(0.2 \mathrm{~g})$ activated with plasma-generated $\mathrm{O}_{3}$ at room temperature for $30 \mathrm{~min}$ (A) with boiling $35 \%$ aqueous solution of $\mathrm{H}_{2} \mathrm{O}_{2}$ for $4 \mathrm{~h}$ (B).

catalyst. The selectivity toward ethylene was calculated as the molar ratio of ethylene obtained to acetylene converted, the same for ethane, while the selectivity toward $\mathrm{C}_{x>2}$ (including the material deposited on the catalytic bed which was not detected by the GC) was considered as the complement of the sum of the previous two, as shown in equations (13). All selectivities are expressed in percentage.

$$
\begin{gathered}
S_{\mathrm{C} 2 \mathrm{H} 4}=\frac{n_{\mathrm{C} 2 \mathrm{H} 4}}{n_{0, \mathrm{C} 2 \mathrm{H} 2}-n_{\mathrm{C} 2 \mathrm{H} 2}}[\%] \\
S_{\mathrm{C} 2 \mathrm{H} 6}=\frac{n_{\mathrm{C} 2 \mathrm{H} 6}}{n_{0, \mathrm{C} 2 \mathrm{H} 2}-n_{\mathrm{C} 2 \mathrm{H} 2}}[\%] \\
S_{\mathrm{C} x>2}=1-S_{\mathrm{C} 2 \mathrm{H} 6}-S_{\mathrm{C} 2 \mathrm{H} 4}[\%]
\end{gathered}
$$

\section{Results and Discussion}

3.1. Characterization of the Surface Functional Groups on the CNF/SMF Inconel Support (TPD and XPS analysis). The $\mathrm{CNF}$ grown on $\mathrm{SMF}_{\text {Inconel }}$ are intrinsically hydrophobic since they consist of graphene sheets. The surface chemistry can be modified by oxidative treatment, changing the polarity of the $\mathrm{CNF}$ by introducing new functional groups. These new groups, often O-containing, impact the electronic properties of the $\mathrm{Pd}$ nanoparticles on the support. ${ }^{29}$ The conventional procedure used to activate CNF is by wet oxidation with $\mathrm{HNO}_{3}$, $\mathrm{HNO}_{3} / \mathrm{H}_{2} \mathrm{SO}_{4},{ }^{30}$ or $\mathrm{H}_{2} \mathrm{O}_{2} \cdot{ }^{13}$ During this study, we applied a new method for the CNF oxidation by gas-phase plasma-generated $\mathrm{O}_{3}{ }^{31}$ It was compared to the wet oxidation in boiling $\mathrm{H}_{2} \mathrm{O}_{2}$. Furthermore, the type and the concentration of surface oxygen groups obtained by these two oxidative pretreatments were determined.

Figure 1 shows the TPD profiles of $\mathrm{CNF} / \mathrm{SMF}_{\text {Inconel }}$ pretreated with $\mathrm{O}_{3}$ and with $\mathrm{H}_{2} \mathrm{O}_{2}$. Both oxidation methods form Ocontaining groups, which decompose during the TPD run, giving $\mathrm{CO}_{2}$ and $\mathrm{CO}$. The results obtained from the TPD were dependent on the heating rate, ${ }^{32,33}$ but the release of $\mathrm{CO}_{2}$ at temperature $T$ $<650 \mathrm{~K}$ could be attributed to carboxylic groups. ${ }^{34,35}$ The $\mathrm{CO}_{2}$ peaks at higher temperature are possibly related to the decomposition of acid derivatives, such as lactones and anhydrides. $\mathrm{CO}$ evolution comes from phenolic, carbonyl, and quinone groups at temperatures $>800 \mathrm{~K} \cdot{ }^{32,36}$ As seen from the XPS spectra presented in Figure 2, the surface oxygen content of untreated $\mathrm{CNF} / \mathrm{SMF}_{\text {Inconel }}$ is negligible since only carbon was found in the spectrum (2a), while in spectrum $2 \mathrm{~b}$ the characteristic oxygen peak appears. Further XPS studies over the two differently modified supports are in progress to assign fitted peaks from the O1s spectra to different functional groups. Even if the total amount of functional groups is almost the same for 


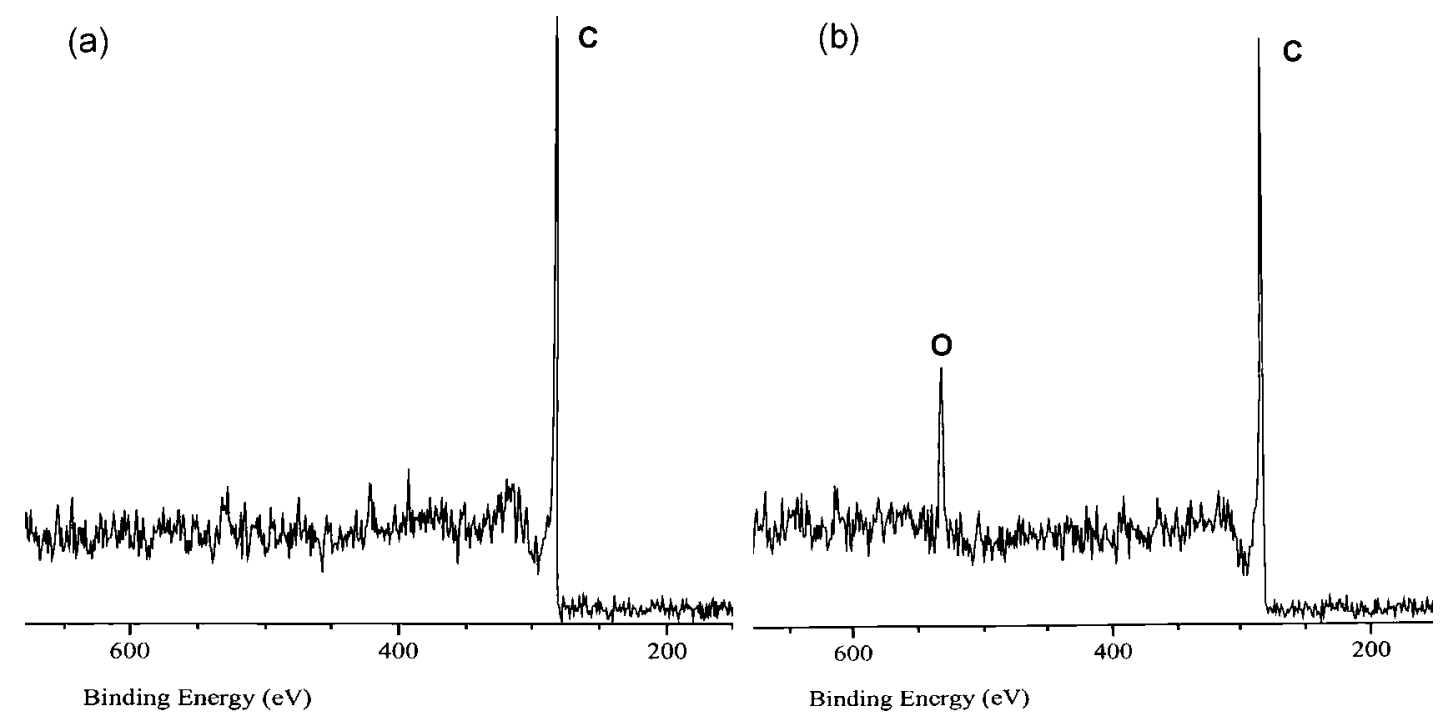

Figure 2. XPS spectra for $\mathrm{C}$ and $\mathrm{O}$ regions of $\mathrm{CNF} / \mathrm{SMF}_{\text {Inconel }}$ (a) untreated, (b) after oxidative treatment.

TABLE 2: Concentration of $\mathrm{CO}$ and $\mathrm{CO}_{2}$ Released from $\mathrm{CNF}_{\mathrm{SMF}}$ Inconel during (a) TPD after Pretreatment, (b) TPD after Pretreatment and Subsequent Reductive Treatment in $10 \% \mathrm{H}_{2}$ in Ar (total flow $150 \mathrm{~mL}(\mathrm{STP}) / \mathrm{min}$ ) at $423 \mathrm{~K}$ for $2 \mathrm{~h}$

\begin{tabular}{|c|c|c|c|c|}
\hline activation treatment & $\begin{array}{c}\mathrm{CO}^{\mathrm{a})} \\
\left(\mathrm{mmol} \mathrm{g}^{-}\right.\end{array}$ & $\begin{array}{c}\mathrm{CO}^{\mathrm{b})} \\
\left(\mathrm{mmol} \mathrm{g}^{-}\right.\end{array}$ & $\begin{array}{l}\mathrm{CO}_{2}{ }^{\mathrm{a})} \\
\mathrm{amol} \mathrm{g}^{-}\end{array}$ & $\begin{array}{c}\left.\mathrm{CO}_{2}{ }^{\mathrm{b}}\right) \\
\left(\mathrm{mmol} \mathrm{g}^{-1}\right)\end{array}$ \\
\hline plasma & 3.6 & 2.3 & 2.9 & 1.2 \\
\hline
\end{tabular}

TABLE 3: Characteristics of Catalyst Performance at 20 min On-Stream $(423 \mathrm{~K}$, total flow $700 \mathrm{~mL}(\mathrm{STP}) / \mathrm{min}(2 \%$ $\mathrm{C}_{2} \mathrm{H}_{2}, 4 \% \mathrm{H}_{2}$ in $\left.\mathrm{Ar}\right)$ )

\begin{tabular}{lccc}
\hline catalyst & initial TOF $\left(\mathrm{s}^{-1}\right)$ & $\begin{array}{c}\text { initial conversion } \\
(\%)\end{array}$ & $\begin{array}{c}\text { initial selectivity } \\
(\%)\end{array}$ \\
\hline A & 15 & 36 & 1 \\
B & 23 & 47 & 59 \\
C & 24 & 43 & 62 \\
D & 14 & 31 & 64 \\
E & 18 & 39 & 64 \\
F & 7 & 24 & 60
\end{tabular}

both activation treatments, as shown in Table 3, the $\mathrm{O}_{3}$-based treatment gives a higher yield of $\mathrm{O}$-groups which leads to $\mathrm{CO}_{2}$, during the TPD $<700 \mathrm{~K}$, being assigned to carboxylic groups. We can therefore conclude that the $\mathrm{O}_{3}$-based treatment, as compared to hydrogen peroxide, is more efficient in terms of yield at a longer time of $\mathrm{O}_{3}$ exposure. This treatment is suitable for the activation of $\mathrm{CNF} / \mathrm{SMF}_{\text {Inconel }}$ supports.

Nevertheless, since the catalytic tests have been performed at $423 \mathrm{~K}$ in the presence of $\mathrm{H}_{2}$, the support functionality could be different in comparison with the fresh one. Therefore, the TPD profiles of two supports (pretreated with $\mathrm{O}_{3}$ and with $\mathrm{H}_{2} \mathrm{O}_{2}$ respectively) have to be compared after treating them with $10 \%$ $\mathrm{H}_{2}$ in $\mathrm{Ar}$ (total flow $150 \mathrm{~mL}(\mathrm{STP}) / \mathrm{min}$ ) at $423 \mathrm{~K}$ for $2 \mathrm{~h}$. The results are shown in Table 2 and Figure 3. The difference between the two samples in the yield of O-groups evolving $\mathrm{CO}_{2}$ during the TPD is negligible, most probably because during the reductive treatment, a part of the functional groups created by oxidation with $\mathrm{O}_{3}$ is destroyed. We can, therefore, conclude that under the reaction conditions applied during the study the $\mathrm{O}_{3}$-pretreated supports become slightly less acidic than $\mathrm{H}_{2} \mathrm{O}_{2}$-pretreated supports.

3.2. High Resolution Transmission Electron Microscopy (HRTEM) Characterization of the ME-Derived Pd Nanoparticles on CNF. Figure 4 shows two HRTEM micrographs of Pd nanoparticles supported on CNF. A bundle of CNF with

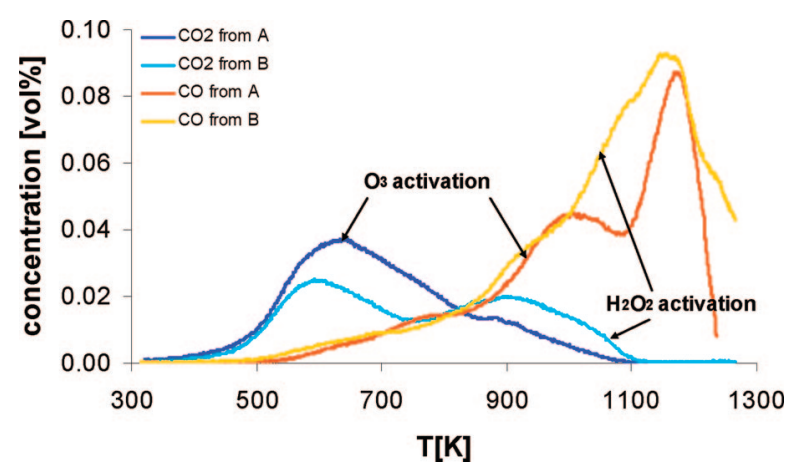

Figure 3. TPD profiles of $\mathrm{CNF} / \mathrm{SMF}_{\text {Inconel }}$ samples $(0.1 \mathrm{~g})$ activated with plasma-generated $\mathrm{O}_{3}$ at room temperature for $30 \mathrm{~min}$ (A) with boiling $35 \%$ aqueous solution of $\mathrm{H}_{2} \mathrm{O}_{2}$ for $4 \mathrm{~h}$ (B) after reductive treatment in $10 \% \mathrm{H}_{2}$ in $\mathrm{Ar}$ (total flow $150 \mathrm{~mL}(\mathrm{STP}) / \mathrm{min}$ ) at $423 \mathrm{~K}$ for $2 \mathrm{~h}$.

\section{SCHEME 1: Reaction Network during Acetylene Hydrogenation ${ }^{7}$}

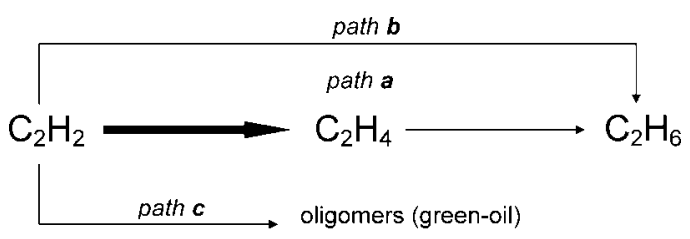

$\mathrm{Ni}$ particles on the top is visible. Ni particles are the catalyst for the CNF growth from the bulk Inconel, ${ }^{18,37}$ and they do not detach from the CNF/SMF Inconel support. The CNF structure corresponds to a platelet type with diameters up to $100 \mathrm{~nm} .^{20,38}$ The micrographs show the monodispersed 11-nm-sized Pd nanoparticles deposited on the CNF surface confirmed by in situ EDX. Some smaller (5 $\mathrm{nm}$ ) unsupported particles were also observed, but in situ EDX analysis revealed the Fe nature of these particles, which probably leached from $\mathrm{SMF}_{\text {Inconel }}$ support during the ultrasonic treatment.

3.3. Size-sensitivity of acetylene hydrogenation (Pd nanoparticle sizes: 8, 11, $13 \mathrm{~nm}$ ). 3.3.1. TOF Dependence on $\mathrm{Pd}$ Particle Size. The Pd size effect on the acetylene hydrogenation was studied over monodispersed particles of 8, 11, and $13 \mathrm{~nm}$ prepared by the ME method (catalysts A, B, C). As seen in Figure 5, the initial TOF (at 20 min on-stream) of acetylene hydrogenation increases with the particle size from 8 to $11 \mathrm{~nm}$ and practically did not change from 11 to $13 \mathrm{~nm}$. The electronic 


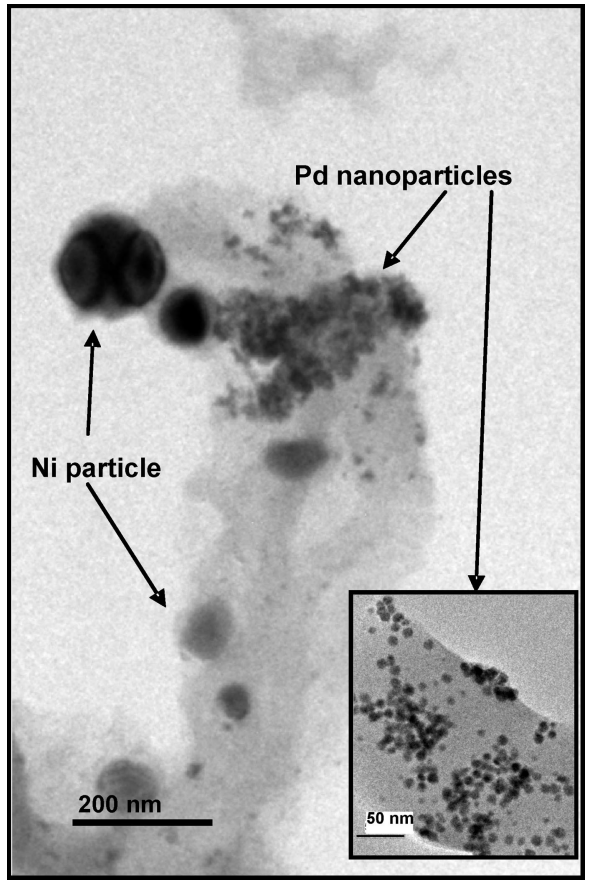

Figure 4. HRTEM micrographs of 11-nm-sized Pd nanoparticles supported on a carbon nanofiber. Inset: 11-nm-sized Pd nanoparticles at higher magnification.

effect cannot explain this behavior, since at particle size greater than $5 \mathrm{~nm}$, Pd shows bulk metallic electronic properties., ${ }^{1,3}$ The geometric effect instead suggests why at lower Pd dispersion the catalyst is more active. Carbonaceous deposits on the metal surface formed in the initial stage of the reaction diminish the Pd surface available for the adsorption of acetylene. ${ }^{39}$ As it has been recently confirmed, carbon deposition and formation of a $\mathrm{Pd}-\mathrm{C}_{x}$ surface phase are structure-sensitive reactions and modify the structure of the Pd surface. ${ }^{12}$ On smaller particles the ratio between surface $\mathrm{C}$ and $\mathrm{Pd}$ is higher, so the available surface for the reaction is diminished, and consequently the TOF observed are smaller. Therefore, in line with the hypothesis of Borodzinsky, ${ }^{6}$ our study suggests the "geometric factor" as the most probable cause for the antipathetic structure-sensitivity of acetylene hydrogenation. As the TOF of the reaction carried out with 11 and $13 \mathrm{~nm}$ particles are almost the same, we can

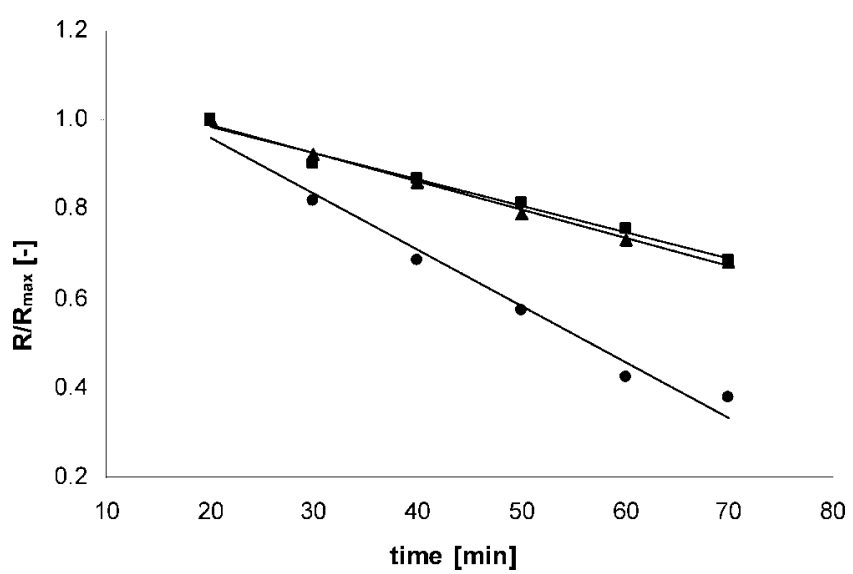

Figure 6. Ratio of reaction rate $(R)$ over initial reaction rate $\left(R_{\max }\right)$ for catalysts $-\mathrm{A}, \boldsymbol{\Delta} \mathrm{B}, \boldsymbol{\mathrm { C }}$ with time on-stream at $423 \mathrm{~K}$, total flow $700 \mathrm{~mL}(\mathrm{STP}) / \mathrm{min}\left(2 \% \mathrm{C}_{2} \mathrm{H}_{2}, 4 \% \mathrm{H}_{2}\right.$ in $\left.\mathrm{Ar}\right)$.

conclude that $11 \mathrm{~nm}$ is a "critical" diameter, above which the nanoparticles' specific activity is not size-dependent. This is a significant finding, as it allows specification of the size of supported Pd nanoparticles attaining Pd bulk specific catalytic activity in acetylene hydrogenation. A similar study on the Pd size-sensitivity was carried out by us for the 1-hexyne hydrogenation where $14 \mathrm{~nm}$ particle specific catalytic activity approached that of Pd black. ${ }^{14}$ This again confirms that the "geometric factor" governs the size-sensitivity: larger 1-hexyne molecules require more space than acetylene on the Pd surface for an optimal adsorption mode.

3.3.2. Initial Selectivity to Ethylene and to Byproduct. The network of the reactions taking place during the hydrogenation of acetylene is depicted in Scheme $1,{ }^{7}$ where three possible paths are outlined. The desired product ethylene is obtained through path a. The overhydrogenation of acetylene takes place through consecutive ethylene hydrogenation or in parallel via path $b$ directly to ethane. The product distribution was analyzed in terms of selectivities toward different products. The initial selectivity to ethylene (after $20 \mathrm{~min}$ on-stream) was $60 \pm 2 \%$, as shown in Table 3 for catalysts A, B, and C, independently on the Pd dispersion. The result is in line with the reported for 1-hexyne hydrogenation, where the selectivity did not change with particle size. ${ }^{14}$ As shown in Figure 5 for catalysts A, B, and $\mathrm{C}$, the byproduct distribution is also independent of the $\mathrm{Pd}$

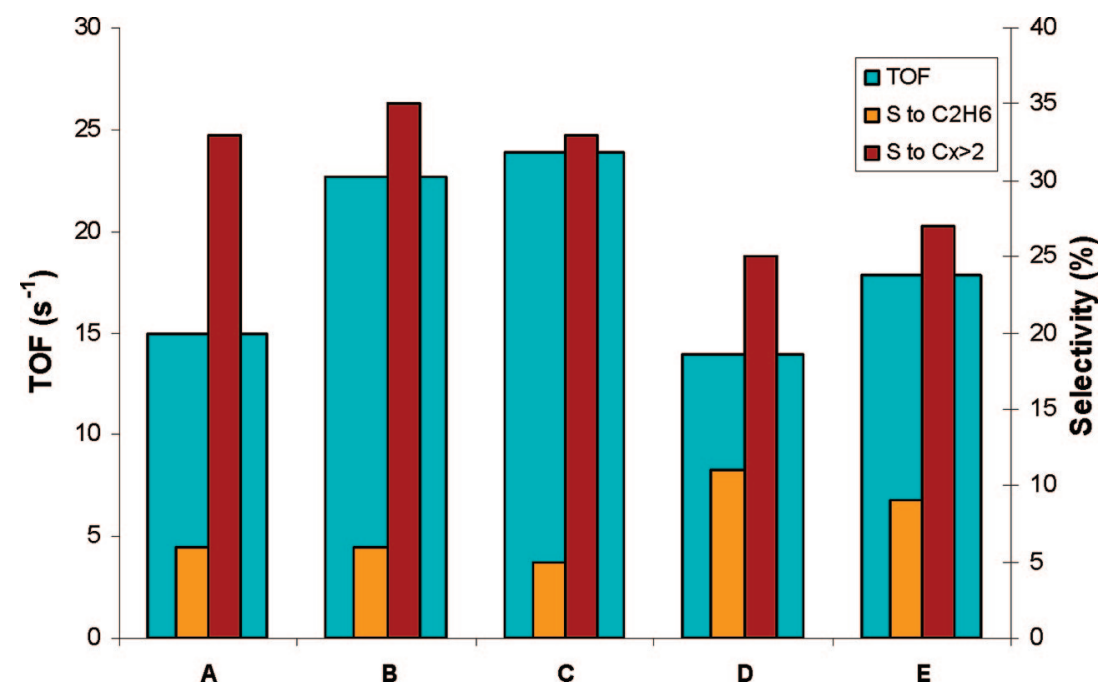

Figure 5. Initial turnover frequency and selectivity toward ethane and oligomers at 20 min on-stream (initial selectivity to ethylene: see Table 2) (423 K, total flow $700 \mathrm{~mL}(\mathrm{STP}) / \mathrm{min}\left(2 \% \mathrm{C}_{2} \mathrm{H}_{2}, 4 \% \mathrm{H}_{2}\right.$ in $\left.\mathrm{Ar}\right)$ ). 


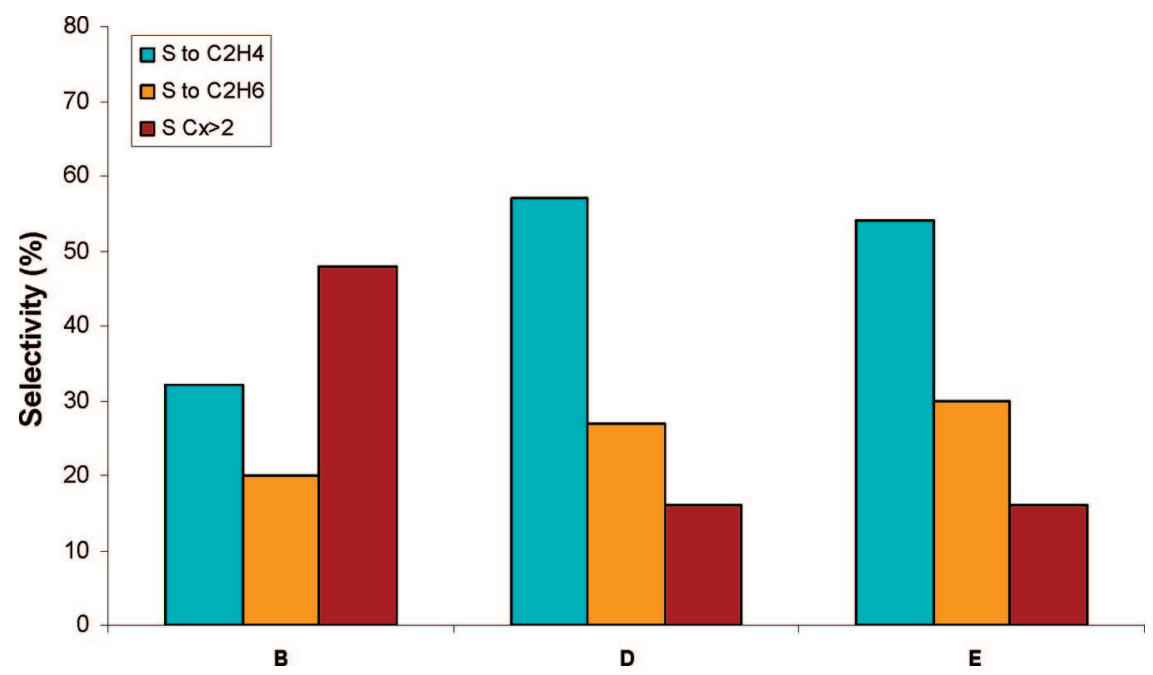

Figure 7. Distribution of products after $6 \mathrm{~h}$ on-stream for catalysts $\mathrm{B}, \mathrm{D}$, and $\mathrm{E}$ at $423 \mathrm{~K}$, total flow $700 \mathrm{~mL}(\mathrm{STP}) / \mathrm{min}^{(2 \%} \mathrm{C}_{2} \mathrm{H}_{2}, 4 \% \mathrm{\textrm {H } _ { 2 }}$ in $\left.\mathrm{Ar}\right)$.

dispersion. These results suggest that the particle size does not change the reaction mechanism and/or the adsorption mode of acetylene and ethylene during the initial stage of the reaction. Thus, the "geometric" nature of the size effect is furthermore confirmed.

3.3.3. Deactivation Rate Dependence on Pd Particle Size. The relationships on the size sensitivity were analyzed during the initial stage of the reaction because the catalysts are known to deactivate due to the carbonaceous deposition. The catalysts $\mathrm{A}, \mathrm{B}$, and $\mathrm{C}$, prepared by microemulsion technique, exhibited a higher deactivation rate compared to the catalyst $\mathrm{F}$ prepared by ion-exchange. This can be attributed to residuals of AOT surfactant on the Pd surface. The presence of sulfur from AOT on the Pd surface is known to promote isomerization/oligomerization compared to overhydrogenation. ${ }^{40}$ Since the AOT traces are present, acetylene oligomerization is favored, and so the catalyst deactivates faster. Figure 6 shows the relative reaction rate evolution for catalysts $\mathrm{A}, \mathrm{B}$, and $\mathrm{C}$ (prepared with the same ME method but with different Pd particle size) during the first $70 \mathrm{~min}$ on-stream. The smaller particles $(8 \mathrm{~nm})$ deactivate faster because the available surface is rapidly covered by green-oil, while particles of 11 and $13 \mathrm{~nm}$ deactivate slower. Interestingly, the deactivation of nanoparticles with size above $11 \mathrm{~nm}$ is not size-dependent.

3.4. Influence of the Support Nature on the Catalytic Behavior (Pd nanoparticles of $11 \mathrm{~nm}$ ). 3.4.1. TOF Dependence on Acidity of the CNF Support. The nature of the catalyst support is known to influence the catalytic behavior of nanoparticles, modifying their morphology and surface chemistry. ${ }^{41}$ However, studies of the catalyst support effect are often complicated due to the difference in active metal dispersion and preparation methods. In this work, Pd nanoparticles of $11 \mathrm{~nm}$ were prepared via a ME technique and then deposited on differently activated CNF supports (see Table 1, catalysts B, $\mathrm{D}$, and E). As the Pd dispersion was kept constant, the effect of the catalyst support on catalytic properties can be considered. After the oxidative treatment, the total acidity of the catalyst supports D and E increases. Carboxyl, quinone, and lactone groups are acidic, while phenolic, carbonylic, and ether groups are weakly acidic to neutral, thus IEP of activated carbon is around 2. Nevertheless, under the reaction conditions catalyst $\mathrm{E}$ is slightly less acidic than catalyst $\mathrm{D}$ (see paragraph 3.1). As shown in Table 3 and Figure 5, the more the catalyst is "acid", the less it is active in terms of TOF. Because of the lower electronic density of the activated CNF as compared to the CNF nontreated, ${ }^{42}$ the electronic properties of $\mathrm{Pd}$ nanoparticles may be affected, increasing the strength of acetylene adsorption. This may cause a decrease of the reaction rate, resulting in lower TOF observed. These results are in line with the reported pulseflow experiments for propyne hydrogenation over acidic $\mathrm{Pd} /$ $\mathrm{SiO}_{2}$ and neutral $\mathrm{Pd} / \mathrm{Al}_{2} \mathrm{O}_{3}$ catalysts with $33 \%$ and $29 \% \mathrm{Pd}$ dispersion. ${ }^{43}$ During the initial reaction period, $\mathrm{Pd} / \mathrm{SiO}_{2}$ showed $60 \%$ lower TOF than the alumina-based catalyst.

3.4.2. Initial Selectivity to Ethylene and to Byproduct. The initial selectivity to ethylene and the byproduct distribution were analyzed for catalysts B, D, and E. This allowed elucidation of the influence of support acidity since the Pd nanoparticle size was kept constant. As shown in Table 3 and Figure 5, it was found that selectivity to ethylene is slightly higher on "acidic" catalysts D and E (64\%) compared to B (59\%). At the same time, a smaller amount of oligomers is formed. These results are in line with the study made by Jackson et al. for propyne hydrogenation $^{43}$ which reported that the "acidic" catalyst retained 3 times less carbon on its surface after 1 pulse of propyne and 16 times less after reaching a steady state. Similarly, it was shown for Pd particles deposited on differently treated activated carbons by the inelastic neutron scattering technique $^{30}$ that the higher the carbon acidity, the less carbonaceous deposits are formed. The herein observed effect of acidity on the catalyst selectivities can be rationalized considering a change in the adsorption strength of acetylene/ethylene (see paragraph 3.4.1). Indeed on "acidic" catalysts the strength of acetylene adsorption is enhanced compared to the ethylene adsorption, so overhydrogenation via path a decreases and the selectivity to ethylene slightly increases. It can also be supposed that the acetylene adsorption mode changes as well, so the intermediate species which are known to transform to ethane $e^{7,11,44}$ via path $\mathrm{b}$ are preferentially formed, diminishing the formation of oligomers via path $\mathrm{c}$.

3.4.3. Selectivity to Ethylene and Byproduct of Aged Catalysts. Figure 7 presents the product distribution over aged $\mathrm{B}, \mathrm{D}$, and $\mathrm{E}$ catalysts (after $6 \mathrm{~h}$ on-stream). The selectivity to ethylene decreased drastically on catalyst B, as compared with the initial selectivity reported in Table 3 , in favor of ethane formation with smaller increase of selectivity to oligomers. Interestingly, the "acidic" catalysts D and E showed after aging a much lower decrease in ethylene selectivity (from $64 \%$ to $55 \%$ ), but the selectivity to ethane increased up to $\sim 30 \%$, 
concomitant with less oligomer formation. It is known that upon aging, the accumulation of hydrocarbonaceous species causes the spillover of hydrogen to the adsorbed species and the rate of hydrogenation of ethylene to ethane (path a) increases. ${ }^{7,11}$ Larsson et al. proposed that the coke formed on the catalyst could be of two types: ${ }^{45}$ one harmful (formed in the lack of hydrogen) which causes the formation of ethane via path a and another harmless which does not modify the selectivity. We can therefore suppose that harmful coke forms much more on catalyst B than on catalysts D and E. As shown for the initial reaction period (see paragraph 3.4.2), oligomers form much less on the "acidic" catalysts, so the hydrogen spillover should be less pronounced. The enhanced ethane formation is therefore supposedly preponderant via path $\mathrm{b}$ (direct overhydrogenation of acetylene to ethane) instead of path a. The need for a lower quantity of oligomers for maintaining high selectivity to ethylene after aging is confirmed with the catalysts F, since it does not show any change in selectivity to ethylene after $6 \mathrm{~h}$ on-stream because of twice lower oligomer formation than for ME-derived catalysts.

\section{Conclusions}

1. Monodispersed Pd nanoparticles prepared from reverse microemulsion $(\mathrm{ME})$ and supported on $\mathrm{CNF} / \mathrm{SMF}$ Inconel were applied for studying the size effect during acetylene hydrogenation. TOF was found to increase from $15 \mathrm{~s}^{-1}$ up to $24 \mathrm{~s}^{-1}$ with the $\mathrm{Pd}$ particle size increase in the range of $8-13 \mathrm{~nm}$. A diameter of $11 \mathrm{~nm}$ was found to be "critical" above which the nanoparticles' specific activity is not size-dependent. This size effect below $11 \mathrm{~nm}$ is suggested to be "geometric" in nature due to the size-sensitive formation of a $\mathrm{Pd}-\mathrm{C}_{x}$ phase. ${ }^{12}$ For smaller particles the $\mathrm{C} / \mathrm{Pd}$ ratio is higher, and carbonaceous deposits block a major part of the active Pd surface. The product distribution was found independent of particle size, confirming the "geometric" nature of the size effect.

2. The deactivation of $\mathrm{Pd}$ due to the oligomer formation was found to vary with the particle size and the presence of sulfur traces coming from AOT surfactant used during the ME preparation of the Pd nanoparticles. Smaller particles $(8 \mathrm{~nm})$ were deactivated faster than the bigger particles $(11-13 \mathrm{~nm})$. The catalysts containing ME-derived Pd nanoparticles were deactivated faster than the catalyst with Pd deposited by ionexchange.

3. The influence of the support nature on the catalytic activity was investigated by comparing the initial TOF of $11-\mathrm{nm} \mathrm{Pd}$ particles supported on differently modified $\mathrm{CNF} / \mathrm{SMF} \mathrm{Inconel}_{\text {. The }}$ initial TOF was found to decrease with the acidity increase of the CNF surface, while the selectivity to ethylene slightly increased. The byproduct (ethane and oligomers) distribution was found shifted toward the ethane formation on "acidic" supports. The observed effects were attributed to the lower electronic density of the activated CNF which affects the strength and mode of acetylene adsorption.

4. After $6 \mathrm{~h}$ on-stream, coke formation on the catalyst causes a decrease of activity and of selectivity to ethylene. This decrease was less pronounced for CNF-based supports with higher acidity obtained by oxidative pretreatment with $\mathrm{H}_{2} \mathrm{O}_{2}$ or with plasma-generated $\mathrm{O}_{3}$.

Acknowledgment. The authors thank Mrs. D. Laub and Dr. M. Cantoni for the HRTEM and EDX, Mr. N. Xanthopoulos for the XPS measurements, and Dr. S. Challapalli for the assistance using the DBD-plasma reactor. Financial support from the Swiss National Science Foundation is highly appreciated.

\section{References and Notes}

(1) Che, M.; Bennett, C. O. Adv. Catal. 1989, 36, 55.

(2) Gigola, C. E.; Aduriz, H. R.; Bodnariuk, P. Appl. Catal. 1986, 27, 133.

(3) Ryndin, Y. A.; Nosova, L. V.; Boronin, A. I.; Chuvilin, A. L. Appl. Catal. 1988, 42, 131.

(4) Sarkany, A.; Weiss, A. H.; Guczi, L. J. Catal. 1986, 98, 550.

(5) Boitiaux, J. P.; Cosyns, J.; Vasudevan, S. Appl. Catal. 1983, 6, 41.

(6) Borodzinski, A. Catal. Lett. 2001, 71, 169.

(7) Molnar, A.; Sarkany, A.; Varga, M. J. Mol. Catal. A: Chem. 2001, 173,185

(8) Silvestre-Albero, J.; Rupprechter, G.; Freund, H. J. J. Catal. 2006, 240,58 .

(9) Semagina, N.; Renken, A.; Laub, D.; Kiwi-Minsker, L. J. Catal. 2007, 246, 308.

(10) Van Hardeveld, R.; Hartog, F. Surf. Sci. 1969, 15, 189.

(11) Borodzinski, A.; Bond, G. C. Catal. Rev. Sci. Eng. 2006, 48, 91.

(12) Teschner, D.; Vass, E.; Hävecker, M.; Zafeiratos, S.; Schnörch,

P.; Sauer, H.; Knop-Gericke, A.; Schlögl, R. J. Catal. 2006, 242, 26.

(13) Tribolet, P.; Kiwi-Minsker, L. Catal. Today 2005, 105, 337.

(14) Semagina, N.; Renken, A.; Kiwi-Minsker, L. J. Phys. Chem. C. 2007, 111, 13933.

(15) Boutonnet, M.; Kizling, J.; Stenius, P. Colloids Surf. 1982, 5, 209.

(16) Eriksson, S.; Nylen, U.; Rojas, S.; Boutonnet, M. Appl. Catal., A 2004, 265, 207.

(17) Zarur, A. J.; Ying, J. Y. Nature 2000, 403, 65.

(18) Tribolet, P.; Kiwi-Minsker, L. Catal. Today 2005, 102, 15.

(19) Rodriguez, N. M.; Kim, M. S.; Baker, R. T. K. J. Phys. Chem.

1994, 98, 13108

(20) Serp, P.; Corrias, M.; Kalck, P. Appl. Catal., A 2003, 253, 337.

(21) Lam, W. K.; Lloyd, L. Oil Gas J. 1972, 27, 66.

(22) Bond, G. C.; Dowden, D. A.; Mackenzie, N. Trans. Faraday Soc.

$1958,54,1537$.

(23) Borodzinski, A.; Cybulski, A. Appl. Catal., A 2000, 198, 51.

(24) Sarkany, A. React. Kinet. Catal. Lett. 2001, 74, 299.

(25) Sarkany, A.; Guczi, L.; Weiss, A. H. Appl. Catal. 1984, 10, 369.

(26) Sarkany, A.; Weiss, A. H.; Szilagyi, T.; Sandor, P.; Guczi, L. Appl. Catal. 1984, 12, 373.

(27) Subrahmanyam, C.; Magureanu, A.; Renken, A.; Kiwi-Minsker, L. Appl. Catal., B 2006, 65, 150 .

(28) Bezemer, G. L.; van Laak, A.; van Dillen, A. J.; de Jong, K. P. Cobalt supported on carbon nanofibers - a promising novel Fischer-Tropsch catalyst In Natural Gas Conversion Vii, 2004; Vol. 147, p 259.

(29) Rodriguez-Reinoso, F. Carbon 1998, 36, 159

(30) Albers, P.; Burmeister, R.; Seibold, K.; Prescher, G.; Parker, S. F.;

Ross, D. K. J. Catal. 1999, 181, 145.

(31) Subrahmanyam, C.; Bulushev, D. A.; Kiwi-Minsker, L. Appl. Catal., B 2005, 61, 98 .

(32) Figueiredo, J. L.; Pereira, M. F. R.; Freitas, M. M. A.; Orfao, J. J. M. Carbon 1999, 37, 1379.

(33) Boehm, H. P. Carbon 2002, 40, 145.

(34) Marchon, B.; Carrazza, J.; Heinemann, H.; Somorjai, G. A. Carbon 1988, $26,507$.

(35) Zhuang, Q. L.; Kyotani, T.; Tomita, A. Carbon 1994, 32, 539.

(36) Zielke, U.; Huttinger, K. J.; Hoffman, W. P. Carbon 1996, 34, 983.

(37) Baker, R. T. K. Carbon 1989, 27, 315.

(38) Paal, Z.; Teschner, D.; Rodriguez, N. M.; Baker, R. T. K.; Toth, L.; Wild, U.; Schlogl, R. Catal. Today 2005, 102, 254.

(39) Ponec, V. Adv. Catal. 1983, 32, 149.

(40) Barbier, J.; Lamy-Pitarea, E.; Marecot, B. J. P.; Cosmys, J.; Verna, F. Adv. Catal. 1990, 37, 279.

(41) Toebes, M. L.; van Dillen, J. A.; de Jong, Y. P. J. Mol. Catal. A: Chem. 2001, 173, 75 .

(42) Zhang, Y. H.; Toebes, M. L.; van der Eerden, A.; O'Grady, W. E.; de Jong, K. P.; Koningsberger, D. C. J. Phys. Chem. B 2004, 108, 18509. (43) Jackson, S. D.; Casey, N. J. J. Chem. Soc., Faraday Trans. 1995, 91,3269

(44) Tysoe, W. T.; Nyberg, G. L.; Lambert, R. M. J. Chem. Soc., Chem. Commun. 1983, 623.

(45) Larsson, M.; Jansson, J.; Asplund, S. J. Catal. 1998, 178, 49.

\section{JP803800W}

